Proceedings

\title{
Autonomous vehicles in sustainable cities: Reclaiming public spaces for people
}

\author{
Maryam Fayyaz ${ }^{1}$, Esther González-González ${ }^{1 *}$ and Soledad Nogués ${ }^{1}$
}

1 GEURBAN research group, School of Civil Engineering (University of Cantabria)

* Correspondence: gonzalezme@unican.es

\begin{abstract}
The advent of autonomous vehicles (AVs) may directly affect current trends in sustainable urbanism based on recovering the urban space for people, active mobility (walking and cycling) and chrono-urbanism. How will AVs affect the urban space and the mobility? How will they change the strategies of street and public space design? are relevant questions that need to be answered to prevent AVs ruling the city as the car has done. Decisions such as setting urban goals and planning ahead and encouraging shared used over ownership, will be crucial in guiding the AVs implementation and achieving the most desirable cities.
\end{abstract}

Keywords: autonomous vehicles; urban design and planning; sustainable mobility; public space

\section{Introduction}

Just as with the arrival of automobiles a century ago, the introduction of autonomous vehicles is expected to bring significant impacts in mobility and urban dynamics. These changes require urban planning and design actions to be undertaken now; however, they are not yet being included in urban plans. This is mainly because there are still few studies on the effects AVs will have on urban form, land use, the interaction with other modes of transportation and thus urban design, which makes them unclear to decision-makers. This article attempts to shed light on these issues, through the literature review of the relation between mobility and use of public space, the expected impacts of AVs on urban space, and the incipient proposals for design strategies for the driverless city, with especial focus on streets and active mobility.

\section{Mobility and public space}

The urban public space, central to urban life, is shaped by two characteristic elements, the square/parks and the street, which have competed over time for increasingly scarce space [1]. The square (and parks) is the exponent of the static dimension, aimed at the stay, recreation and social interaction of citizens. The street represents the dynamic component, which gives access and on which movements take place [2]. Cities were designed at human scale until the industrial revolution when new modes of transport were developed, and mobility began to take on greater prominence in urban design [3]. This is also when the segregation of space is introduced, distinguishing between people and vehicular space, and with it the separation of urban design from traffic engineering [4].

Between the 1920s and 1950s, the development of the automobile brings about one of the biggest changes in urban form and structure in the history of cities, although differed between the United States and Europe. While Americans adopted automobiles immediately for all trips [5], the old continent, thanks to the compactness of its cities, continued to rely on walking and public transport. After World War Two, the automobile becomes the king of the city. Planning was devoted to achieving ever more efficient routes in terms of speed, so that urban motorways/highways and more traffic lanes appear [6], 
along with the need and demand for parking, however pavements, the space for people, 1 was reduced to a minimum.

Currently, we are seeing a call for the reconquest of the city as a response to what Gehl and Gemzøe [7] call the car-invaded and even abandoned city. This reconquest seeks a return to the traditional citizen-dominated city, centred on reclaiming public space and the street. This is embodied in new urban models that have been greatly recently due to the COVID-19 pandemic. One of these models is superblocks launched in Barcelona (Spain), whose aim is to group adjacent blocks into a superblock defined by the perimeter roads where vehicle circulate, and whose internal space is freed for other uses, such as green areas and small squares [8]. Another one corresponds to chrono-urbanism, the 15-minute city or 20-minute neighbourhood, of which one of the most emblematic advocates is the city of Paris. This model is based on the idea that most daily basic activities should be accessed within this timeframe, either by walking or cycling in the European context [9] or including public transportation or transit in the American one [10]. Another major contribution is tactical urbanism, low-cost temporary interventions that show the benefits for citizens and boost public acceptance [11] of actions such as replacing traffic and parking with new public spaces. These interventions have generated a large and positive social impact in cities such as Berlin, New York, Amsterdam or Bogotá [9] and can play a very important role in demonstrating how AVs can improve cities and people's lives [12].

\section{Expected impacts of AVs on urban space}

The effects that are expected to generate the greatest opportunity for redesign in the city are those related to the reduction of the parking space and the space dedicated to vehicular traffic.

In large cities, between $15 \%$ and $30 \%$ of urban space is devoted to parking, either onstreet or off-street [13]. The arrival of AVs could lead to an overall decrease in parking demand between $67 \%$, in case private AVs are encouraged, to up to $90 \%$ when only a $2 \%$ of shared AVs are implemented [14], also considering that most of the parking would be relocated to large peripheral areas [15]. This means, that in large cities between $10 \%$ to $27 \%$ or urban space could be released. However, these benefits will not be as significant in peripheral areas, where only $50 \%$ of trips are expected to be shared (compared to $90 \%$ in cities) [16] or in rural areas, where there are only 2.2 parking spaces per vehicle compared to 4 in urban ones [17].

As for traffic space, both the number and width of lanes might be reduced thanks to the decrease of the number of circulating vehicles (more shared AVs -SAVs), platooning and the implementation of reversible lanes [18]. Schlossberg et al. [19] indicate that, for example, for a typical four-lane arterial street with on-street parking, considering a feasible width reduction of the drive lanes to 8 feet $(2,45 \mathrm{~m})$ and the elimination of one parking lane and one traffic lane, $40 \%$ of the space $(32$ feet $-9,8 \mathrm{~m})$ will be released. In general, releases of $15-25 \%$ of the street space could be achieved [13], which implies for a city like Lisbon, where $30 \%$ of its urban space corresponds to road infrastructure, a release of $6 \%$ of total urban space [20].

But AVs can also generate effects that may hinder the achievement of the city's reconquest objectives. Some authors point to a possible 26 and $20 \%$ reduction in the share of walking and cycling respectively in the case low-cost SAVs are implemented. However, if private AVs were banned or SAVs were operated at high costs, the walking share could benefit by $22-31 \%$ [21].

\section{Design strategies for public space in the driverless city}

The advent of AVs will present a major urban design challenge, and an opportunity to enhance a design based on the needs of people over vehicles, especially thanks to the reduction in car space. On the one hand, it would allow the widening of pavements to improve the pedestrian realm $[19,22]$. This proposal is taken up in most studies, despite 
the potential expense of replacing the underground utility infrastructure [23]. On the other hand, it would create more dedicated lanes for public transport, as well as bicycle lanes and other personal mobility vehicles to travel short distances and their parking spaces [24]. Indeed, the possibilities for reuse are enormous, from increasing green areas to the configuration of social spaces (for social interaction/meetings), conviviality and leisure or the development of street commerce [25,2627]. Although some experts already point to the preference of green areas in large surface parking spaces and new cycleways in onstreet parking areas [27].

Within the street platform, competition for space from various uses is anticipated to be particularly intense in the curb space, where in addition to traditional uses, new ones such as micro-mobility transit, and especially passenger boarding and alighting for ondemand mobility services and shared mobility and package and food deliveries, whose need is expected to increase significantly with the advent of AVs [24,25], need to be accommodated. The design of these zones should avoid conflicts between AVs and public transport by preventing vehicles from using bus stops to drop-off passengers [28], as well as obstructions, ensuring continuity of pedestrian and cycling routes [22]. The introduction of AVs can enable the design of flexible and dynamic spaces in these areas, where a variety of public and private uses can be developed according to the needs of the moment, and even vary throughout the day [26].

With regard to the specific proposals for redesigning the street and public space, logically, they vary according to the technical characteristics and functionality of these spaces. For example, depending on aspects such as the class of the street (local, collector, arterial, expressway) [20] or the speed and use intensity [12], the type or location of the space (city centre, suburban, neighbourhood) [13]. Other authors propose the gradual adoption of design proposals according to the degree of introduction of AVs [22], or "plug and play" solutions that are gradually implemented to form connected networks of public squares, pedestrian, commercial and green spaces [29].

\section{Conclusion}

In recent years, we have seen a push for new urban models that aim to recover public space for people instead of cars, laying the grounds for the urban planning goals that will guide the coming decades. The arrival of AVs can revolutionise the urban systems, causing effects that can help or hinder this sustainable path. The magnitude and final character of these impacts will depend on the type of settlement and critical decisions such as encouraging shared used over privately-owned vehicles.

In line with new trends, all emerging design strategies for the driverless city are based on the elimination or reduction of traffic space and parking lanes, and their conversion into spaces devoted to people, active mobility modes and public transport, while providing a high quality that attracts citizens, essential to ensure the use of modern public spaces [7].

This revision demonstrates the potential of AVs for transforming the urban environment, but also the vital need to start planning now for the cities we want, to establish and implement the most citizen-friendly urban design strategies that will commit us to the most win-win model of AV implementation.

Funding: "This research was funded by Spanish Ministry of Science and Innovation, grant number PID2019-110355RB-I00".

Conflicts of Interest: The authors declare no conflict of interest.

\section{References}

2. Krier, R. Urban Space. Academic Editions: London, UK, 1979. ISBN 0856705764 
3. Newman, P.; Kenworthy, J. Sustainability and Cities: Overcoming Automobile Dependence; Island Press: Washington DC, USA, 1 1999.

4. Hamilton-Baillie, B. Urban design: Why don't we do it in the road? Modifying traffic behavior through legible urban design. Journal of Urban Technology 2004, 11(1), 43-62. https://doi.org/10.1080/1063073042000341970

5. Rodrigue, Jean-Paul. The Geography of Transport Systems, 5th Ed. Routledge: New York, 2020. 456p. ISBN 978-0-367-36463-2

6. Hall, P. The City on the Highway. The Automobile Suburb: Long Island, Wisconsin, Los Angeles, Paris, 1920-1987. in Cities of Tomorrow. Oxford: Basil Blackwell Ltd., 1988.

7. Gehl, J., Gemzøe, L. Winning back public space. In Sustainable transport; Trolley, R., Ed.; Woodhead Publishing Limited: London, UK, 2003; pp. 97-106.

8. Rueda, S. Superblocks for the design of new cities and renovation of existing ones: Barcelona's case. In Integrating human health into urban and transport planning: A framework; Nieuwenhuijsen, M., H. Khreis, H., Eds.; Springer: Berlin, Germany, 2019; pp. 135-153. https://doi.org/10.1007/978-3-319-74983-9 8

9. Moreno, C.; Allam, Z.; Chabaud, D.; Gall, C.; Pratlong, F. Introducing the "15-Minute City": Sustainability, Resilience and Place Identity in Future Post-Pandemic Cities. Smart Cities 2021, 4, 93-111. https://doi.org/10.3390/smartcities4010006

10. Capasso Da Silva, D.; King, D.A.; Lemar, S. Accessibility in practice: 20-minute city as a sustainability planning goal. Sustainability 2020, 12, 129.

11. Silva, P. Tactical urbanism: Towards an evolutionary cities' approach? Enviromental Planning B: Planning and Design 2016, 43, 1040-1051.

12. Riggs, W.; Appleyard, B.; Johnson, M. A design framework for livable streets in the era of autonomous vehicles. Urban, Planning and Transport Research 2020, 8(1), 125-137.

13. WSP|Parsons Brinckerhoff and Farrells. Making better places: autonomous vehicles and future opportunities, 2016. Available online: https://www.wsp.com/-/media/z-floating-images/Documents/UK/Making-better-places.pdf (accessed on 30 November 2021).

14. Milakis, D.; van Arem, B.; van Wee, B. Policy and society related implications of automated driving: A review of literature and directions for future research. Journal of Intelligent Transportation Systems, 2017, 21(4), 324-348. https://doi.org/10.1080/15472450.2017.1291351

15. Zakharenko, R. Self-driving cars will change cities. Regional Science and Urban Economics, 2016, 61, $26-37$. https://doi.org/10.1016/j.regsciurbeco.2016.09.003

16. Alessandrini, A.; Campagna, A.; Delle Site, P.; Filippi, F.; Persian, L. Automated vehicles and the rethinking of mobility and cities. Transportation Research Procedia 2015, 5, 145-160. https://doi.org/10.1016/j.trpro.2015.01.002

17. Chester, M.; Horvath, A.; Madanat, S. Parking infrastructure and the environment. ACCESS Magazine 2011, 1(39), $28-33$.

18. Heinrichs, D. Autonomous driving and urban land use. In Autonomous driving: Technical, legal and social aspects; Maurer, M., Gerdes, J.C., Lenz, B, Winner, H., Eds.; Springer: Berlin, Germany, 2016; pp. 213-231.

19. Schlossberg, M.; Riggs, W. W.; Millard-Ball, A.; Shay, E. Rethinking the street in an era of driverless cars. UrbanismNext, 2018.

20. Fortes, M. B. Tecnologias disruptivas e mobilidade urbana: inovações para o desenho das cidades. PhD Thesis, Faculdade de Arquitetura e Urbanismo, Universidade de São Paulo, Brasil, 2020.

21. Soteropoulos, A.; Berger, M.; Ciari, F. Impacts of automated vehicles on travel behaviour and land use: An international review of modelling studies. Transport Reviews 2019, 39(1), 29-49. https://doi.org/10.1080/01441647.2018.1523253

22. Chapin, T.; Stevens, L.; Crute, J. Envisioning Florida's future: Transportation and land use in an automated vehicle world. Final report of Florida Department of Transportation (FDOT) contract BDV30 934-10, 2016. Florida Department of Transportation: Tallahassee, USA, 2016.

23. De Lara, S. The driverless city. How will AVs shape cities in the future? Master of Design In Strategic Foresight And Innovation, OCAD University, Toronto, Ontario, Canada, 2020.

24. Howell, A.; Chamberlain, K.L. (Eds.) Multilevel Impacts of Emerging Technologies on City Form and Development. Urbanism Next Center, Univeristy of Oregon, 2020. Available at: https://cpb-us-e1.wpmucdn.com/blogs.uoregon.edu/dist/f/13615/files/2020/01/NSF-Report All-Chapters FINAL 013020.pdf

25. Mitman, M. F.; Davis, S.; Armet, I. B.; Knopf, E. Curbside Management Practitioners Guide. Institute of Transportation Engineers: Washington, DC., USA, 2018 https://www.ite.org/pub/?id=C75A6B8B-E210-5EB3-F4A6-A2FDDA8AE4AA

26. NACTO. Blueprint for Autonomous Urbanism Second Edition. Designing Cities. National Association of City Transportation Officials, New York, 2019. Available at: https://nacto.org/publication/bau2/ (accessed 30 November 2021).

27. Nogués, S., González-González, E.; Cordera, R. New urban planning challenges under emerging autonomous mobility: evaluating backcasting scenarios and policies through an expert survey. Land Use Policy 2020, 95, 104652. https://doi.org/10.1016/j.landusepol.2020.104652

28. Nappa, S. Autonomous potential: Complete streets in an autonomous vehicle future. Professional Project Report, Master of Community and Regional Planning, University of Oregon, USA, 2018.

29. FXcollaborative. Public Square, 2017. Available online: http://www.fxcollaborative.com/projects/186/public-square/ (accessed 30 November 2021). 